\title{
Coping with Stress During the Second Wave of the COVID-I 9 Pandemic by Polish University Students: Strategies, Structure, and Relation to Psychological Well-Being
}

\author{
Monika Guszkowska (D), Anna Dąbrowska-Zimakowska \\ Department of Rehabilitation, Jozef Pilsudski University of Physical Education in Warsaw, Warsaw, Poland \\ Correspondence: Monika Guszkowska, Department of Rehabilitation, Jozef Pilsudski University of Physical Education in Warsaw, Marymoncka 34, \\ Warsaw, 00-968, Poland, Tel +48 2283404 31/269, Email monika.guszkowska@awf.edu.pl
}

\begin{abstract}
Purpose: The aim of the study was to establish a hierarchy of strategies and the structure of copIng with the stress of the COVID-19 pandemic by university students and the relationship between coping strategies and psychological well-being.

Participants and Methods: An exploratory study was conducted using a cross-sectional research design. The study involved 1330 university students, aged 18 to 30 years. The Brief COPE Scale, being the Polish adaptation by Juczyński and Ogińska-Bulik, and the short version of the Psychological General Well-Being Index (authors' adaptation) were used.

Results: Acceptance, doing something else, active coping, and physical activity were the most commonly used strategies for coping with stress during the second wave of the pandemic. Substance use, denial, and behavioral disengagement were lowest in the hierarchy of coping strategies. Female and master's students used a variety of strategies more than male and bachelor's students. Coping strategies correlated significantly with psychological well-being. Four second-degree factors were distinguished, explaining $55.1 \%$ of the total variation: maladaptive coping, coping by support, by positive reappraisal, and by action. Stepwise regression analysis confirmed the importance of the second-degree factors as predictors of psychological well-being.

Conclusion: Our findings show that young adults studying at the university of physical Education in Poland used adaptive strategies to cope with stress during the second wave of the COVID-19 pandemic. Gender differences in coping with pandemic stress are similar to those found in previous studies. The structure of coping with pandemic stress is to some extent similar, but also partially dependent on various cultural factors.
\end{abstract}

Keywords: pandemic stress, coronavirus, coping, mental health, undergraduates

\section{Introduction}

On 30 January 2020, the World Health Organization (WHO) declared the novel coronavirus 2019-nCoV (COVID-19) a "public health emergency of international concern" (p.1). After a decline in infection rates and a brief return to a relatively normal life for citizens, and functioning economies in the summer, the fall of 2020 saw the so-called second wave of the pandemic, with much higher rates of infections and deaths from COVID-19, resulting in further lockdowns in many countries. In many European countries, October and November 2020 saw the highest rates of illness and deaths due to coronavirus 2019-nCoV infection. A similar pattern was observed in Poland. In October 2020, at the beginning of the academic year 2020/2021, the majority of students at Polish universities started to continue education based on the hybrid learning model, and, after a short period of time, the deterioration of the epidemic caused a shift to entirely remote learning.

Closure of schools, social distancing, and changes in lifestyles have led to a serious deterioration in the mental health of young people..$^{2-4}$ In Polish university students, a significant increase in the level of depression was also observed as the pandemic progressed. ${ }^{5}$ As shown by the results of our research, which has not been published yet, during the second 
wave of the pandemic, a significant number of students at a large university of physical education in Poland declared a deterioration of mood compared to the pre-pandemic period. ${ }^{6}$

According to the cognitive-motivational-relational theory by Lazarus and Folkman, ${ }^{7}$ and the Antonovsky salutogenic model, ${ }^{8}$ the stress transaction costs, both in terms of physical and mental health, depend to a large extent on the effectiveness of the process of coping with stress. Coping has been defined as

a constantly changing cognitive and behavioral effort to manage specific external and/or internal demands that are appraised as taxing or exceeding the resources of the person. (p.141)

The coping process consists of strategies, specific cognitive and behavioral efforts aimed at reducing or avoiding the effect of a stressor, undertaken in a specific stress transaction. Only some strategies are effective, ie, they allow the individual to effectively reduce the intensity of stress, and so, coping can be categorized into adaptive and maladaptive strategies. ${ }^{9}$ Adaptive coping strategies decrease emotional distress and are linked with better psychological adjustment; whereas maladaptive coping strategies are associated with more severe symptoms of psychological responses after stressful experiences. ${ }^{10,11}$ The effectiveness of the strategy depends to a large extent on the characteristics of the stressor or, more broadly, on the stressful situation. ${ }^{12,13}$

Coping strategies can have either protective or damaging effects on mental health. The emotion-focused (emotion expression, rumination, self-blame) and passive coping strategies (thinking avoidance, denial, behavioral disengagement, using alcohol, self-isolation) are usually found to have a negative impact on mental health. Problem-focused and active coping strategies (positive thinking, acceptance, humor, planning, positive reframing, optimism, social support) most often have a beneficial impact on mental health. ${ }^{14-18}$

It is widely believed that coping strategies play an important role in emotional responses and the development of psychological problems during outbreaks of viral infections. ${ }^{19,20}$ Common coping strategies during previous pandemics include problem-focused coping, seeking social support, and positive appraisal of the situation. ${ }^{21,22}$ During the first wave of the COVID-19 pandemic, American adults most often dealt with stress through distraction, active coping, and seeking emotional support. ${ }^{23}$ Acceptance, humor, and planning were the three most common strategies used by adults in Greece. More dysfunctional strategies (denial, substance use, and giving up) were more rarely used. ${ }^{24}$ Some interesting research done in Russia, Kyrgyzstan, and Peru found that the most frequently reported coping strategies for stress as a result of the COVID19 pandemic, measured by the Brief COPE scale, were acceptance, active coping, planning, and positive reframing. The least frequently used coping behaviors were substance use, denial, behavioral disengagement, and religion. ${ }^{25}$

As mentioned previously, college students experience high levels of stress, also related to the pandemic, and are at risk for stress-related mental and physical health disorders. ${ }^{26}$ It is, therefore, important to understand not only their response to the COVID-19 pandemic but also how they cope with the stress caused by the pandemic. Undergraduate students at small American colleges employed significantly more maladaptive coping strategies such as denial, selfblame, and disengagement than the general population. ${ }^{27}$ American undergraduate social work students most frequently used acceptance, venting, seeking emotional support, self-distraction, and planning, while substance use, self-blame, and behavioral disengagement were the least used. ${ }^{28}$ In the group of Polish students studying physical education, acceptance, then positive reframing, planning, and active coping were at the top of the hierarchy of strategies for coping with stress during the first wave of the COVID-19 pandemic. ${ }^{29}$ The question arises as to whether the frequency of using different strategies during the second wave of the pandemic, 8 months after its initial outbreak, was similar. No data on coping with stress during the second wave of the COVID-19 pandemic have been found in the available literature. It can be assumed that after 8 months, psychological adaptation to a stressful situation occurred in a significant part of students, and the coping strategies used became more effective.

Based on the results of previous research conducted during the first wave of the pandemic, we make the following hypothesis:

$\mathrm{H}_{1}$ : During the second wave of the COVID-19 pandemic, Polish students of physical education university most often used the following strategies: acceptance, active coping, physical activity and positive reframing. 
There are different classifications of ways to deal with stress. The earliest and simplest division relates to two goals of coping: changing the situation and alleviating its unpleasant emotional effects, which correspond to two functions of the coping process in the classic concept of Lazarus and Folkman. ${ }^{7}$ The theoretical approach to coping with stress by these authors includes at least two main criteria that can become the basis for the classification of coping strategies: modality (cognitive - behavioral) and functional criterion (problem solving - emotion regulation). However, the authors did not use these criteria in further attempts to classify coping strategies. They relied more on empirical behavior, using factor analysis to establish overarching categories for describing coping with stress. Carver, Scheier and Weintraub, ${ }^{30}$ the authors of the COPE inventory, declared to base their classification on a theoretical basis. However, the strategies include both those distinguished on the basis of the analysis of the coping process and those described in previous empirical studies. To describe their results in more general terms, researchers often use factor analysis. In the aforementioned studies conducted in Russia, Kyrgyzstan, and Peru, in all three countries, the coping responses were associated with the same four coping domains: problem-focused coping, socially supported coping, avoidance, and emotion-focused coping. ${ }^{25}$ The results suggest that during the COVID-19 pandemic, people from different countries applied the full range of coping responses within the four universal coping factors. We suppose that the classification established by the researchers is universal.

$\mathrm{H}_{2}$ : Coping strategies combine into four domains: problem-focused coping, socially supported coping, avoidance, and emotion-focused coping.

Findings concerning the strategies that are effective in coping with pandemic-related stress are inconclusive but were positively related to active coping, use of emotional support, and turning to religion, and negatively related to humor as a coping strategy in a study conducted in Germany. ${ }^{31}$ In a survey of a representative sample of adult Austrians, Budimir, Probst, and Pieh $^{32}$ found that positive thinking, active stress coping, and social support were positive predictors for psychological quality of life and well-being, and negative predictors for perceived stress, depression, anxiety, and insomnia. Alcohol and cigarette consumption and support in faith were positive predictors for these mental problems. Research during Australia's first wave of the pandemic found that positive reframing, acceptance, and humor were associated with better mental health. Conversely, self-blame, venting, behavioral disengagement, and self-distraction were associated with poorer mental health. ${ }^{33}$ It can be assumed, however, that, at least in part, the discrepancies result from demographic and cultural differences. In our research, we adopted psychological well-being as an indicator of the effectiveness of coping. The question is then which strategies for coping with the stress of a pandemic are positively linked, and which are negatively linked, to student well-being during the second wave of COVID-19.

Based on the knowledge about the effectiveness of coping with stress and the results of research on these issues during a pandemic, we assumed that:

$\mathrm{H}_{3}$ : The psychological well-being of students during the second wave of the COVID-19 pandemic is positively related to the use of strategies such as acceptance, positive reframing, active coping and physical activity.

$\mathrm{H}_{4}$ : Students' psychological well-being is negatively related to self-blame, venting and substance use.

The study aimed to establish a hierarchy of strategies and the structure of coping with the stress of the COVID-19 pandemic by university students, any differences by gender, level, and place of study, and the relationship between coping strategies and psychological well-being.

\section{Materials and Methods}

\section{Study Design}

An exploratory study was performed using a cross-sectional research design in November 2020, during the second wave of the COVID-19 pandemic when the level of quarantine restrictions was high. The research was conducted using the online anonymous survey included psychological questionnaires. Basic personal data was also collected. 
The participants willingly and voluntarily participated in the research. The online form of informed consent was obtained from all participants included in the study. The IRB approval of the Senate Research Ethics Committee at Jozef Pilsudski University of Physical Education in Warsaw (SKE 01-13/2021) was obtained for the study design and data collection. All procedures were in accordance with the APA ethical standards, and the 1964 Helsinki Declaration and its later amendments or comparable ethical standards.

\section{Participants}

The study involved 1330 students at the Jozef Pilsudski University of Physical Education in Warsaw, Poland, which accounts for about one-third of all current students, aged 18 to 30 years $(M=20.81 \pm 1.92)$, and comprising 767 women (57.7\%) and 563 men (42.3\%). The study covered 1036 (77.9\%) bachelor's and 294 (22.1\%) master's students studying full-time in a large city with over 1.5 million inhabitants $(\mathrm{n}=945 ; 71.1 \%)$, and in a branch in a small city with approximately 57 thousand inhabitants $(\mathrm{n}=385 ; 28.9 \%)$, of the following university majors: physiotherapy $(\mathrm{n}=421)$, physical education $(n=375)$, tourism and recreation $(n=188)$, sport $(n=142)$, nursing $(n=88)$, occupational therapy ( $n$ $=80)$, and cosmetology $(\mathrm{n}=36)$. In statistical analysis, the last three university majors were combined into one group called "others".

\section{Measures}

\section{Strategies for Coping with Stress}

The brief COPE (The Coping Orientations to Problems Experienced) inventory, ${ }^{30}$ being the Polish adaptation by Juczyński and Ogińska-Bulik, ${ }^{33}$ was used. The scale consists of 28 statements with a 4-point response format (from 0 - I almost never do this to 3 - I almost always do this) and measures the frequency of use of 14 coping strategies. The Polish version is characterized by satisfactory reliability and validity.

The scale was completed with two statements regarding the use of physical activity as a coping strategy (I exercise intensively, run, and cycle, to feel better; I engage in sport/physical activity to not think about the problem). The instructions asked respondents to answer what they did to cope with the stress caused by the COVID-19 pandemic. The original format of the responses has been retained.

In our study, half-reliability coefficients were calculated (Spearman-Brown coefficient 0.740; Guttman split-half coefficient 0.734), and Cronbach's alpha coefficients lower than 0.600 were obtained for the following scales: Doing something else 0.304; Venting 0.384; Humor 0.512; Acceptance 0.570; Active coping 0.584. Cronbach's alpha coefficients were the highest in the case of Substance use 0.921; Turning to religion 0.868; and Physical activity 0.864 .

\section{Psychological Well-Being}

The short version of the Psychological General Well-Being Index ${ }^{35}$ was used. The PGWBI is a measure of the level of subjective psychological well-being and its short version consists of six items measuring: anxiety - Have you been bothered by nervousness or your "nerves" during the past month?; Vitality - How much energy, pep, or vitality did you have or feel during the past month?; I felt tired, worn out, used up, or exhausted during the past month; Depressed mood - I felt downhearted and blue during the past month; Self-control - I was emotionally stable and sure of myself during the past month; Positive well-being - I felt cheerful, lighthearted during the past month. The answers were given on a 6-point Likert scale. The coefficients for the English version of Cronbach's alpha in the different studies were all above 0.80, thereby showing acceptable reliability, as well as when compared to the original instrument in full length (22 items). ${ }^{36}$ Cronbach's alpha for the Polish version used in our research was 0.853 .

\section{Statistical Analysis}

Three-way analysis of variance was used to determine the differences between men and women, people studying in the capital and a small town, and at the level of bachelor's and master's. The relationships between the variables were determined using $r$ Pearson's correlation coefficients. Exploratory factor analysis using the principal components method with VARIMAX rotation and Kaiser normalization was performed to identify the second-degree factors of the Brief 
COPE Scale. Stepwise regression analysis was used to determine predictors of psychological well-being during the pandemic.

\section{Results}

\section{Coping Strategies}

Table 1 presents the descriptive statistics of students' results on the Brief COPE Scale. Respondents declared that they most often used the acceptance strategy (submitting to the reality of the situation). High in the hierarchy was also the strategy of doing something else (engaging in other activities so as not to think about the event). Active coping (active or direct actions to overcome a stressful situation) was ranked third. Taking up physical activity to deal with stress was ranked fourth; we can treat this strategy as avoidance (I practice so as not to think about stress) or emotional (I exercise to relieve tension caused by a pandemic). Seeking emotional support (looking for empathy and understanding from others) was ranked fifth.

Students least often declared substance use (using alcohol, drugs, or medications to distract from a stressful situation), denial (refusing to believe what happened), and turning to religion (appealing to God, faith, religion, or meditation for help) strategies.

Data on the comparison of strategies for coping with stress depending on gender, place of study, and level of study (bachelor vs master) are available in the Supplementary Material (Table S1).

\section{Gender}

The frequency of using nine coping strategies differed significantly depending on gender. Female students reported more frequent use of many strategies: seeking emotional and instrumental support (asking others for advice, help, or information), venting (expressing negative emotions), doing something else, denial, behavioral disengagement (refusing to actively deal with the stress), and planning (thinking about how to deal with a difficult situation). Men obtained higher scores on only 3 scales: physical activity, humor (making jokes and laughing about the situation), and substance use. The

Table I Brief COPE - Descriptive Statistics

\begin{tabular}{|l|c|c|c|}
\hline Coping Strategies & M & SD & Rank \\
\hline Acceptance & 2.06 & 0.701 & I \\
\hline Doing something else & 1.76 & 0.731 & 3 \\
\hline Active coping & 1.68 & 0.700 & 4 \\
\hline Physical activity & 1.67 & 0.951 & 5 \\
\hline Seeking of emotional support & 1.70 & 0.849 & 6 \\
\hline Positive reframing & 1.63 & 0.816 & 7 \\
\hline Planning & 1.45 & 0.781 & 8 \\
\hline Venting & 1.36 & 0.732 & 9 \\
\hline Seeking of instrumental support & 1.31 & 0.844 & 10 \\
\hline Humor & 1.19 & 0.752 & 11 \\
\hline Self-blaming & 1.06 & 0.912 & 12 \\
\hline Behavioral disengagement & 0.82 & 0.709 & 13 \\
\hline Turning to religion & 0.77 & 0.914 & 14 \\
\hline Denial & 0.73 & 0.801 & 15 \\
\hline Substance use & 0.55 & 0.808 & 2 \\
\hline
\end{tabular}


size of the effect was greatest for seeking emotional and instrumental support and venting, but in these cases, the effect was also only weak.

Interestingly, gender did not differentiate the scores in the most frequently used acceptance strategy, and strategies being quite high in the hierarchy: active coping, planning, and positive reframing (reappraising a stressful situation in a positive way).

\section{Place of Study}

The differences in the frequency of using pandemic stress coping strategies depending on the place of study were less numerous. People studying in a small town more often used the strategy of denial and turning to religion. Students from a large city used the acceptance strategy significantly more often. In all cases, the effect size was small.

\section{Study Level}

The results of the analysis of variance show significant differences in the frequency of using seven coping strategies. Master's students reported more frequent use of the planning, active coping, acceptance, positive reframing, seeking emotional support, and turning to religion strategies. Bachelor's students used denial more frequently. In all cases, the effect size was small.

\section{Interactions Between Variables}

Only three statistically significant interactions with a small effect were found. In the case of substance use and behavioral disengagement, this occurred between the place of study and the level of studies (See Supplementary Material; Figures S1 and $\underline{\mathrm{S}}$ ). Among those studying in a large city, master's students were more likely to use both strategies, and among those studying in a small city - bachelor's students. At the first level of studies, both strategies were more often used by students from a small city, while at the second level - from a large city.

In the case of acceptance, there was a statistically significant difference between gender and place of study (Figure 3S; Supplementary Material). Among men, students from a small town achieved higher results, and the results of women were similar. Among people studying in a large city, men obtained slightly higher results, and among students from a small town - women. However, the size of the effect was small.

\section{Coping Strategies and Psychological Well-Being}

The strongest relationships were noted for the self-blaming (criticizing and accusing oneself) $(r=.-.484 ; p<0.001)$, behavioral disengagement $(r=-0.393 ; p<0.001)$, and venting $(r=-0.300 ; p<0.001)$ strategies. Frequent use of these strategies negatively correlated with psychological well-being. Substance use $(r=-0.190 ; p<0.001)$, denial $(r=-0.183$; $p<0.001)$, and doing something else $(r=-0.181 ; p<0.001)$ were also negatively correlated with psychological wellbeing. The correlation coefficient for seeking instrumental support $(r=-0.075 ; p=0.006)$ had the same sign, but a smaller value. Psychological well-being was positively correlated with positive reframing $(r=0.272 ; p<0.001)$, physical activity $(r=0.261 ; p<0.001)$, acceptance $(r=0.205 ; p<0.001)$, humor $(r=0.180 ; p<0.001)$, and active coping $(r=0.132 ; p<0.001)$. The correlation coefficients were higher in the case of maladaptive strategies, negatively related to psychological well-being.

\section{The Structure of Coping with the Pandemic Second-Degree Factors of the Brief COPE}

In order to determine the structure of coping with the pandemic in the studied group of students, exploratory factor analysis was performed using the principal components method with VARIMAX rotation and Kaiser normalization. The Kaiser-Meyer-Olkin measure of the adequacy of the sample selection $(\mathrm{KMO}=0.763)$, and the Bartlett sphericity test $\left(\mathrm{chi}^{2}=4639 ; p<0.001\right)$ confirmed the advisability of conducting factor analysis. Four second-degree factors were distinguished, explaining $55.1 \%$ of the total variation. The matrix of rotated components is provided in the Supplementary Material (Table S2).

The first factor, explaining $22.4 \%$ of the common variation, is made up of 5 strategies (factor loadings are given in parentheses): behavioral disengagement (0.730), self-blaming (0.689), denial (0.653), substance use (0.633), and venting 
(0.538). They are emotional and avoidant in nature. In the light of the results of the previous research discussed in the introduction, all these strategies can be considered maladaptive, which is why we have called this factor maladaptive coping. The second factor, which we called coping by seeking support, covers three strategies: seeking instrumental (0.854) and emotional (0.812) support, and turning to religion (0.337) and explains $16.4 \%$ of the common variance. The third factor includes four strategies: active coping (0.742), physical activity (0.736), planning (0.579), and doing something else (0.434) and explains $8.4 \%$ of the common variance. These strategies are related to taking different actions or planning them, so we propose calling this factor coping by actions. The last and fourth factor, called coping by positive reappraisal, explains $7.9 \%$ of the variance and includes 3 cognitive strategies related to the acceptance and positive interpretation of the situation: humor (0.794), acceptance (0.607), and positive reframing (0.572). We treat these factors as the domains of coping with the stress of the COVID-19 pandemic.

\section{Coping Domains}

In order to compare the frequency of using different coping domains, the sum of points in the items making up a given second-degree factor was divided by their number, thereby obtaining indicators ranging from 0 to 3 . The table presenting the descriptive statistics for the second-degree factors in the entire study group, and by gender, level of study, and place of study, is available in Supplementary Material (Table S3).

The hierarchy of coping domains, determined on the basis of group means, is as follows: 1 . Coping by actions $(M=$ $1.64 \pm 0.548) ; 2$. Coping by positive reappraisal $(M=1.63 \pm 0.539) ; 3$. Coping by seeking support $(M=1.26 \pm 0.651) ; 4$. Maladaptive coping $(M=0.90 \pm 0.534)$.

The differences by gender, place, and level of study were small. Women obtained slightly higher scores in coping by seeking support and maladaptive coping, master's students obtained higher results in coping by actions, by positive reappraisal, and by seeking support. In all cases, the size of the effect was small.

\section{Coping Domains and Psychological Well-Being}

Table 2 shows the correlation coefficients between coping domain and psychological well-being. All domains were correlated with each other at the level $p<0.001$. The only negative and slight correlation was between maladaptive coping and coping by positive reappraisal. The strongest but only moderately positive relationship occurred between coping by actions and by seeking support as well as by positive reappraisal. The remaining correlations were weak.

A negative, moderate correlation was found between psychological well-being and maladaptive coping. Coping by positive reappraisal correlated positively with psychological well-being and was slightly weaker. The positive correlation for coping by actions was statistically significant but very small. Only coping by seeking support did not correlate significantly with psychological well-being.

The regression analysis results for psychological well-being are shown in Table 3. The importance of the domains of coping with stress as predictors of psychological well-being was confirmed. The strongest negative predictor was maladaptive coping. Both positive predictors of coping by positive reappraisal and by actions were less predictive for the psychological well-being of students during the second wave of the COVID-19 pandemic. Additionally, gender was

Table 2 Correlations Between Coping Domains and Psychological Well-Being (Pearson's r)

\begin{tabular}{|l|c|c|c|c|}
\hline Variables & $\begin{array}{c}\text { Maladaptive } \\
\text { Coping }\end{array}$ & $\begin{array}{c}\text { Coping by Seeking } \\
\text { Support }\end{array}$ & $\begin{array}{c}\text { Coping by } \\
\text { Actions }\end{array}$ & $\begin{array}{c}\text { Coping by Positive } \\
\text { Reappraisal }\end{array}$ \\
\hline Maladaptive coping & & $0.215^{*}$ & $0.142^{*}$ & $-0.098^{*}$ \\
\hline Coping by seeking support & & & $0.361^{*}$ & $0.247^{*}$ \\
\hline Coping by actions & & & & $0.330^{*}$ \\
\hline Psychological well-being & $-0.464^{*}$ & 0.005 & $0.096^{*}$ & $0.310^{*}$ \\
\hline
\end{tabular}

Note: $* p<0.001$. 
Table 3 Predictors of Psychological Well-Being - Stepwise Regression Analysis

\begin{tabular}{|c|c|c|c|c|c|c|}
\hline Step & Predictor & $\beta$ & $R^{2}$ & $F ; p$ & $\Delta R^{2}$ & $F ; p$ \\
\hline I. & Maladaptive coping & -0.464 & 0.215 & $364.55 ;<0.00 \mathrm{I}$ & & \\
\hline \multirow[t]{2}{*}{2.} & Maladaptive coping & -0.438 & \multirow[t]{2}{*}{0.285} & \multirow[t]{2}{*}{$265.80 ;<0.001$} & \multirow[t]{2}{*}{0.071} & \multirow[t]{2}{*}{$|3| .29 ;<0.00 \mid$} \\
\hline & Coping by positive reappraisal & 0.267 & & & & \\
\hline \multirow[t]{3}{*}{3.} & Maladaptive coping & -0.412 & \multirow[t]{3}{*}{0.325} & \multirow[t]{3}{*}{$213.88 ;<0.001$} & \multirow[t]{3}{*}{0.040} & \multirow[t]{3}{*}{$78.85 ;<0.001$} \\
\hline & Coping by positive reappraisal & 0.254 & & & & \\
\hline & Gender $(M=1 ; F=2)$ & -0.202 & & & & \\
\hline \multirow[t]{4}{*}{4.} & Maladaptive coping & -0.427 & \multirow[t]{4}{*}{0.330} & \multirow[t]{4}{*}{$164.65 ;<0.001$} & \multirow[t]{4}{*}{0.006} & \multirow[t]{4}{*}{$11.75 ; 0.001$} \\
\hline & Coping by positive reappraisal & 0.225 & & & & \\
\hline & Gender $(M=I ; F=2)$ & -0.203 & & & & \\
\hline & Coping by actions & 0.083 & & & & \\
\hline
\end{tabular}

introduced into the equation. Greater psychological well-being is to be expected in men than in women. The coefficient of determination reached a value of 0.330 .

\section{Discussion}

A pandemic is a universal stressor and causes a sense of helplessness together with the loss of a general sense of security and limits meeting various basic needs, including protection, stability, and the ability to anticipate the future. Thus, effective coping with stress is of particular importance. ${ }^{19,20}$ During the second wave of the COVID-19 pandemic, young Polish adults studying at the University of Physical Education (PE) most often dealt with stress through acceptance, doing something else, active coping and physical activity. A positive reframing was ranked sixth. The first hypothesis: During the second wave of the COVID-19 pandemic, Polish students of physical education university most often used the following strategies: acceptance, active coping, physical activity and positive reframing was thus confirmed. This is partly in line with the results of studies on adults during previous epidemics. ${ }^{21,22}$ During the current pandemic, distraction and active coping were the most commonly used strategies by American adults, ${ }^{23}$ acceptance, humor, and planning were preferred by adults in Greece, ${ }^{24}$ while acceptance, active coping, planning, and positive reframing by respondents in Russia, Kyrgyzstan, and Peru ${ }^{25 .}$ Despite some differences, the results of studies carried out in different countries seem to be similar.

The acceptance strategy that was most often used by our students, is to accept the situation and learn how to live in it without trying to change it. Polish elite athletes and PE students practicing sports most often used this strategy in coping with stress during the first wave of the COVID-19 pandemic. ${ }^{29}$ The acceptance strategy came seventh in terms of the frequency of use by PE students surveyed in 2012-2014. ${ }^{37}$ Thus, in a pandemic situation, Polish students used the acceptance strategy more often than their peers few years earlier in a non-pandemic situation. Acceptance seems like the right way to deal with stress when the situation is beyond the control of the individual, such as in a pandemic. If it is not possible to change the situation, adaptation requires an autoplastic reaction (ie a change in the subject).

Doing something else (a form of distraction) was the second most used coping strategy. In the research on Polish PE students conducted during the first wave of the pandemic, this strategy came in fifth place, ${ }^{29}$ and in studies of PE students in non-pandemic conditions - sixth. ${ }^{37}$ We do not have data on the coping strategies preferred by students we have surveyed in non-pandemic conditions, so we cannot check whether the change in the rank of the distraction strategy is related to adaptation to the stress of the pandemic. However, we suppose that it is. It is believed that cognitive and behavioral avoidance strategies are adaptive in uncontrolled situations such as a pandemic. ${ }^{13}$

Active coping was the third most used strategy by our students. This strategy was most often used by students surveyed by Juczyński and Ogińska-Bulik ${ }^{34}$ and Guszkowska et $\mathrm{al}^{37}$ in non-pandemic conditions. During the first wave 
of the pandemic PE students used it less frequently. ${ }^{29}$ Perhaps they were in the "shock phase" and were trying to cognitively process a new experience, which resulted in frequent use of positive reframing and planning. After a few months, these cognitive strategies were used less frequently and supplemented by concrete actions, reducing the risk of infection (active coping). In American undergraduate social-work students, the use of self-distraction and active coping increased, while denial decreased with the first month of transition to remote learning. ${ }^{28}$

Previous research indicates that such problem-focused and active strategies as acceptance, planning, positive reframing, and active coping are adaptive and maintain mental well-being in stress transactions, ${ }^{14-18,22}$ also during the COVID-19 pandemic. $^{31-33}$ This is confirmed by the results of our research. Psychological well-being was positively correlated with positive reframing, acceptance, and active coping which confirms our third hypothesis: The mental wellbeing of students during the second wave of the COVID-19 pandemic is positively related to the use of strategies such as acceptance, positive reframing, active coping and physical activity. In previous studies of Polish athletes - potential Olympians, positive reframing was the only coping strategy improving the mood during the COVID-19 pandemic. $^{38}$

Physical activity was the fourth most frequently used strategy for coping with the stress of the COVID-19 pandemic by students we surveyed. This strategy was more often used by male students and positively correlated with psychological well-being. Other studies confirm the psychological benefits of exercise during a pandemic. Undergraduate social work students in the United States rated exercise as an effective way of coping with the stress of the pandemic. ${ }^{28}$ Exercise and fitness activities such as jogging, cycling, and indoor exercising were perceived as effective ways of coping with pandemic stress by Australian medical students. ${ }^{39}$ On the other hand, physically inactive Turkish students experienced greater stress, and physical inactivity significantly predicted higher perceived stress. ${ }^{40}$ The belief that physical exercise is a very effective means to calm down during the pandemic was a protective factor against stress in French university students. ${ }^{41}$ Home-based physical activity acted as a protective factor during confinement in university students in Panama. ${ }^{42}$ Similar conclusions can be drawn from studies of the general population. ${ }^{43,44}$ The data from 16,137 individuals from 99 different countries show that people who exercised almost every day during COVID-19 pandemic had the best mood, regardless of their pre-pandemic physical activity. Those who were inactive pre-pandemic and slightly increased their physical activity during the pandemic reported mood similar to those who remained inactive during the pandemic. Those who reduced their exercise frequency during the pandemic reported worse mood compared to those who maintained or increased their pre-pandemic exercise frequency. ${ }^{45}$

Regardless of when the measurement was made, substance use, denial, and behavioral disengagement were the lowest in the hierarchy of coping strategies of students from the University of Physical Education. ${ }^{29,37}$ These strategies are usually considered maladaptive, ${ }^{14-18}$ also as a way to cope with the stress of the COVID-19 pandemic. ${ }^{31-33}$ This is confirmed by the negative correlations we have established between psychological well-being and substance use and denial. It is worth noting that the negative correlations of self-blaming, behavioral disengagement, and venting were stronger, suggesting that these strategies are particularly maladaptive in coping with pandemic stress by university students. These results support our fourth hypothesis: Students' mental well-being is negatively related to self-blame, venting and substance use.

Self-blaming, substance use, and behavioral disengagement were also most strongly related to the decline in mood during the first wave of the COVID-19 pandemic in Polish potential Olympians. ${ }^{38}$ Similar results in the Australian population were obtained by Gurvich et al, ${ }^{33}$ who studied the relationship between coping strategies and mental health. Of course, in the case of correlation, it is impossible to say what is the cause and what is the effect. It is possible for the person experiencing a depressed mood or anxiety to withdraw from the action as well as to try to vent emotions. On the other hand, withdrawing from the activities can further depress the mood, and venting negative emotions can exacerbate them. It is the same with the relationship between self-blaming and mental health, especially depression. ${ }^{13,21}$

Based on the obtained results, it can be concluded that when confronted with the stress of the pandemic, the studied sample of young adults, as a whole, used adaptive coping strategies. Did the frequency of using coping strategies differ by gender? Although significant differences between men and women were observed in most coping strategies, the effect size was small or even negligible. Interestingly, there were no differences in the most commonly used strategies (acceptance, active coping, positive reframing, planning). Female students seem to use a variety of strategies more frequently than men, especially those that are emotional and supportive (venting, seeking emotional and instrumental 
support), but also maladaptive (denial, behavioral disengagement). Male students more frequently used only three strategies: physical activity, humor, and substance use. The differences we identified, at least in part, may have been due to the fact that women are more likely to report coping with stress. ${ }^{13}$ Moreover, seeking support and help is a part of the social role of women. The lower tendency of men to seek or use the available social support in order to cope with stress is explained by fear of being negatively judged. ${ }^{46}$

Similar gender differences were found during the first wave of the pandemic in the group of Polish PE students. ${ }^{29}$ In Pakistan, male students were observed to use planning and humor more frequently, while self-distraction, acceptance, and religious coping less frequently than female students. ${ }^{47}$ Also in the general population in the United States ${ }^{23}$ and Greece, ${ }^{24}$ the differences between women and men in coping with the pandemic stress were similar. Polish PE male students surveyed in 2012-2014 clearly preferred task-oriented strategies, while female students preferred to look for support (instrumental and emotional) and placed higher importance on focusing on and venting of emotions. ${ }^{37}$

The level of studies also significantly differentiated strategies for coping with the stress of the COVID-19 pandemic. Master's students reported more frequent use of proactive and cognitive strategies such as planning, active coping, acceptance, and positive reframing as well as supportive ones like seeking emotional support and turning to religion. Bachelor's students used denial more frequently. Strategies used more frequently by higher-level students appear to be more adaptive, probably due to their greater life experience. More use of maladaptive strategies and less use of adaptation strategies has also been found in younger students in Pakistan. ${ }^{47}$ Huang, Lei, $\mathrm{Xu}$, Liu, and $\mathrm{Yu}^{48}$ found that nursing students were less proactive in using problem-focused coping during the COVID-19 outbreak than nurses, which may have been due to their having less life and professional experience. In a study of a Greek general population, the use of planning and religious coping increased with age, while instrumental support decreased. Denial showed a U-type association with increased use by both the young (18-23) and the elderly. ${ }^{24}$ Voronin et al, ${ }^{25}$ in a cross-cultural comparison of Russia, Kyrgyzstan, and Peru, found that regardless of the country, older participants reported higher active coping, planning, turning to religion, and lower mental disengagement and venting. It is worth noting that in a study by Skapinakis et $\mathrm{al}^{24}$ and Voronin et $\mathrm{al},{ }^{25}$ the age variance was significantly greater than in the studies on students.

The results of the factor analysis do not support the second hypothesis that coping strategies combine into four domains: problem-focused coping, socially supported coping, avoidance, and emotion-focused coping as were found by Voronin et $\mathrm{al}^{25}$ during the COVID-19 pandemic in Russia, Kyrgyzstan, and Peru. In our research, four second-degree factors were distinguished in the Brief COPE inventory: maladaptive coping (behavioral disengagement, self-blaming, denial, substance use, and venting), coping by seeking support (seeking instrumental and emotional support and turning to religion), coping by actions (active coping, physical activity, planning, and doing something else), and coping by positive reappraisal (humor, acceptance, and positive reframing).

The factor structures of the Brief COPE questionnaire obtained in the previous studies differed. In non-pandemic conditions, Hastings et $\mathrm{al}^{49}$ established a four-factor structure for Brief COPE including: active avoidance coping (selfblaming, behavioral disengagement, substance use, venting of emotions, and a statement from the distraction scale), problem-focused coping (active coping, planning, seeking social support, and an element from seeking emotional support), positive coping (humor and positive reframing, and one item each from the acceptance and emotional support scales), and religious/denial coping. Skapinakis et al, ${ }^{24}$ in a study of adult people during the COVID-19 lockdown in Greece, derived two broad factors, positive/active factor, composed of 5 coping strategies (acceptance, humor, planning, positive reframing, and active coping), and a supportive/distractive factor composed of 4 coping strategies (doing something else, venting, emotional support, and instrumental support). The remaining four strategies (religion, denial, substance use, and behavioral disengagement) did not load clearly either of these two factors.

The greatest consistency of the results can be seen in the factor named by us coping by positive reappraisal, by Hastings et $\mathrm{al}^{49}$ - positive coping, and by Voronin et $\mathrm{al}^{25}$ - emotion-focused coping. Also, the factor Hastings et $\mathrm{al}^{49}$ called active $^{2}$ avoidance coping is similar to our factor called maladaptive coping. Previous research indicated that strategies that made up the factor of maladaptive coping were indeed maladaptive, also in a pandemic situation. ${ }^{14-18,22,31-33,50}$ Also in the group we studied, this factor correlated negatively and most strongly with psychological well-being and was its strongest and negative predictor. 
Coping by positive reappraisal correlated positively and moderately with psychological well-being and was a positive predictor, as was positive/active coping identified by Skapinakis et al. ${ }^{24}$ Agha,${ }^{50}$ on the other hand, did not find any relationships between the factor of positive coping distinguished by Hastings et $\mathrm{al}^{49}$ and depression, anxiety, and stress in people living in lockdown during COVID-19 in Saudi Arabia.

Coping by actions was poorly but positively related to the psychological well-being of the students we studied. In a representative sample for Austria, ${ }^{32}$ active coping was a negative predictor for stress, depression, anxiety, and insomnia as well as a positive one for well-being. In contrast, in a group of Chinese nurses and nursing students, problem-focused coping was a positive predictor of anxiety and fear, but it did not allow for the prediction of sadness and anger during the COVID-19 outbreak. ${ }^{48}$ Based on a review of stress research from previous pandemics, Chew et $\mathrm{al}^{21}$ concluded that the use of problem-focused strategies such as problem-solving should predict better adjustment in controllable situations, while emotion-focused strategies such as avoidance and denial would be favored in uncontrollable situations.

Coping by seeking support did not correlate with psychological well-being and was not its predictor. Similar results were obtained by Gurvich et $\mathrm{al}^{33}$ in a study of Australian residents during the first wave of the COVID-19 pandemic. When examining a representative sample of adult Austrians, Budimir et $\mathrm{al}^{32}$ concluded that social support was a positive predictor of quality of life and well-being, and a negative predictor of perceived stress, depression, anxiety, and insomnia. Issues concerning the effects of different ways of coping with pandemic stress on mental health require further research.

\section{Limitations}

This study has certain limitations. Only students from one university were examined, so the possibility to generalize the results is limited. In order to determine whether the observed relationships and differences are characteristic for students of other majors and specializations, as well as for young adults in general, further research is required.

The study design was cross-sectional, so we have obtained data about relationships between coping strategies and psychological well-being, not about the cause-effect dependencies. Of course, no experimental research is possible when assessing the effectiveness of the preferred strategies for coping with the stress of a pandemic.

As a result of the research, we only obtained self-reported data that may be affected by social desirability bias. In the group of PE university students, it may lead to underreporting the frequency of substance use or overreporting physical activity frequency as a coping strategy.

The lack of norms for Brief COPE inventory in the Polish population made it impossible to precisely interpret the results; they could only be compared with the average results of university students obtained in the process of culturally adapting the Brief COPE inventory, and in previous research of PE students in non-pandemic conditions and during the first wave of the COVID-19 pandemic.

Conducting research via the Internet made it necessary to use the shortest and simplest versions of the measurement scales. Probably, the use of the full version of COPE and PGWBI would provide more interesting data on the preferred ways of coping with the stress of the COVID-19 pandemic by Polish students, the factors differentiating these preferences, their effectiveness in maintaining psychological well-being, and the structure of the coping process.

Despite these limitations, we hope our research helps in increasing our understanding of how university students coped with stress during the second wave of the COVID-19 pandemic.

\section{Conclusion}

Our findings show that young adults studying at the university of physical education in Poland used adaptive strategies to cope with stress during the second wave of the COVID-19 pandemic, preferring acceptance, doing something else, and active coping. Like the inhabitants of other, mainly European countries, as well as Polish students in non-pandemic conditions, and during the first phase of a pandemic, they declared that they least often used strategies commonly considered maladaptive (denial, substance use, behavioral disengagement). It seems that female students used a variety of strategies more than men, especially that are emotional and supportive, but also maladaptive in nature. This may be partly because women are more likely to admit that the situation is difficult and requires coping with stress. 
While the gender differences in coping with pandemic stress are quite similar across cultures and conditions, the relationship between coping strategies and age requires further research, taking into account intercultural differences.

In light of the results of the research conducted so far, it can be concluded that the structure of coping with various stressors is to some extent similar, but also partially dependent on the nature of the stressor and cultural factors. The comparison of the results of studies conducted during the COVID-19 pandemic in different populations suggests that the effectiveness of individual coping styles may vary depending on the environmental and cultural factors.

\section{Data Sharing Statement}

The data that support the findings of this study are available from the corresponding author upon reasonable request.

\section{Funding}

This work was supported by the Ministry of Education and Science in Poland in the year 2021 under Research Group no 4 at Jozef Pilsudski University of Physical Education in Warsaw.

\section{Disclosure}

The authors report no conflicts of interest in this work.

\section{References}

1. World Health Organization. Updated WHO recommendations for international traffic in relation to COVID-19 outbreak; 2020. Available from: https:/www.who.int/news-room/articles-detail/updated-whorecommendations-for-international-traffic-in-relation-to-covid-19-outbreak. Accessed September 20, 2021.

2. Asanov I, Flores F, McKenzie D, Mensmann M, Schulte M. Remote-learning, time-use, and mental health of Ecuadorian high-school students during the COVID19 quarantine. World Dev. 2021;38:105225. doi:10.1016/j.worlddev.2020.105225

3. De Oliveira Araújo FJ, de Lima LSA, Cidade PIM, Nobre CB, Neto MLR. Impact of Sars-Cov-2 and its reverberation in global higher education and mental health. Psychiatry Res. 2020;288(6):112977. doi:10.1016/j.psychres.2020.112977

4. YoungMinds Coronavirus: impact on young people with mental health needs; 2020. Available from: https://youngminds.org.uk/media/4119/ youngminds-survey-with-young-peoplereturning-to-school-coronavirus-report-autumn-report.pdf. Accessed December $20,2020$.

5. Debowska A, Horeczy B, Boduszek D, Dolinski D. A repeated cross-sectional survey assessing university students' stress, depression, anxiety, and suicidality in the early stages of the COVID-19 pandemic in Poland. Psychol Med. 2020:1-4. doi:10.1017/S003329172000392X

6. Guszkowska M, Dąbrowska-Zimakowska A, Tarnowski A. What do mood changes of Polish university students during the second wave of the COVID-19 pandemic depend on? The effect of gender, academic variables and coping. Adv Ment Health. under revision

7. Lazarus RS, Folkman S. Stress, Appraisal, and Coping. New York: Springer; 1984.

8. Antonovsky A. Unravelling the Mystery of Health: How People Manage Stress and Stay Well. San Francisco: Jossey-Bass; 1987.

9. Mahmoud JSR, Staten RT, Hall LA, Lennie TA. The relationship among young adult college students' depression, anxiety, stress, demographics, life satisfaction, and coping styles. Issues Ment Health Nurs. 2012;33(3):149-156. doi:10.3109/01612840.2011.632708

10. Strasshofer DR, Peterson ZD, Beagley MC, Galovsky TE. Investigating the relationship between posttraumatic stress symptoms and posttraumatic growth following community violence: the role of anger. Psychol Trauma. 2018;10(5):515-522. doi:10.1037/tra0000314

11. Dörfel D, Rabe S, Karl A. Coping strategies in daily life as protective and risk factors for post-traumatic stress in motor vehicle accident survivors. $J$ Loss Trauma. 2008;13(5):422-440. doi:10.1080/15325020701742136

12. Lazarus RS. Stress and Emotion: A New Synthesis. New York: Springer; 1999.

13. Heszen I. Psychologia Stresu [Psychology of Stress]. Warszawa: PWN; 2014.

14. Colville GA, Dalia C, Brierley J, Abbas K, Morgan H, Perkins-Porras L. Burnout and traumatic stress in staff working in paediatric intensive care: associations with resilience and coping strategies. Intensive Care Med. 2015;41(2):364-365. doi:10.1007/s00134-014-3559-2

15. Colville GA, Smith JG, Brierle J, et al. Coping with staff burnout and work-related posttraumatic stress in intensive care. Pediatr Crit Care Med. 2017;18(7):e267-e273. doi:10.1097/PCC.0000000000001179

16. Luo T, Cheng X, Xiong Y. Relationship among resilience, coping style and mental health of newly recruited workers born after 1990 in manufacturing industry of Shenzhen City. J Hygiene Res. 2015;44(2):252-256.

17. Naushad VA, Bierens JJ, Nishan KP, et al. A systematic review of impact disaster on the mental health of medical responders. Prehosp Disaster Med. 2019;34(6):632-643. doi:10.1017/S1049023X19004874

18. Rodriguez-Rey R, Palacios A, Alonso-Tapia J, et al. Burnout and posttraumatic stress in paediatric critical care personnel: prediction from resilience and coping styles. Aust Crit Care. 2019;32(1):46-53. doi:10.1016/j.aucc.2018.02.003

19. Sim K, Chan YH, Chong PN, Chua HC, Soon SW. Psychosocial and coping responses within the community health care setting towards a national outbreak of an infectious disease. J Psychosom Res. 2010;68(2):195-202. doi:10.1016/j.jpsychores.2009.04.004

20. Yeung DYL, Fung HH. Age differences and in coping and emotional responses toward SARS: a longitudinal study of Hong Kong Chinese. Aging Ment Health. 2007;11(5):579-587. doi:10.1080/13607860601086355

21. Chew QH, Wei KC, Vasoo S, Chua HC, Sim K. Narrative synthesis of psychological and coping responses toward emerging infectious disease outbreaks in the general population: practical considerations for the COVID-19 pandemic. Singapore Med J. 2020;61(7):350-356. doi:10.11622/ smedj.2020046 
22. Stanislawski K. The coping circumplex model: an integrative model of the structure of coping with stress. Front Psychol. 2019;10:694. doi:10.3389/fpsyg.2019.00694

23. Park CL, Russell BS, Fendrich M, Finkelstein-Fox L, Hutchison M, Becker J. Americans' COVID-19 stress, coping and adherence to CDC guidelines. J Gen Intern Med. 2020;35(8):2296-2303. doi:10.1007/s11606-020-05898-9

24. Skapinakis P, Bellos S, Oikonomou A, et al. Depression and its relationship with coping strategies and illness perception during the COVID-19 lockdown in Greece: a cross-sectional survey of population. Depress Res Treat. 2020;2020:3158954. doi:10.1155/2020/3158954

25. Voronin IA, Manrique-Millones D, Vasin GM, et al. Coping responses during the COVID-19 pandemic: cross-cultural comparison of Russia, Kyrgyzstan, and Peru. Psychol Russia. 2020;13(4):55-74.

26. Hirsch J, Rabon J, Reynolds E, Barton A, Chang E. Perceived stress and suicidal behaviors in college students: conditional indirect effects of depressive symptoms and mental health stigma. Stigma Health. 2019;4(1):98-106. doi:10.1037/sah0000125

27. Munsell SE, O’Malley L, Mackey C. Coping with COVID. Edu Res Theory Pract. 2020;31(3):101-109.

28. Apgar D, Cadmus T. Using mixed methods to assess coping and self-regulation skills of undergraduate social work students impacted by COVID-19. Clin Soc Work J. 2021;1-12. doi:10.1007/s10615-021-00790-3

29. Szczypińska M, Samełko A, Guszkowska M. Strategies for coping with stress in athletes during the COVID-19 pandemic and their predictors. Front Psychol. 2021;12:624949. doi:10.3389/fpsyg.2021.624949

30. Carver CS, Scheier MF, Weintraub JK. Assessing coping strategies: a theoretically based approach. J Pers Soc Psychol. 1989;56(2):267-283. doi:10.1037//0022-3514.56.2.267

31. Zacher H, Rudolph CW. Individual differences and changes in subjective wellbeing during the early stages of the COVID-19 pandemic. Am Psychol. 2021;76(1):50-56. doi:10.1037/amp0000702

32. Budimir S, Probst T, Pieh C. Coping strategies and mental health during COVID-19 lockdown. J Ment Health. 2021;30(2):156-163. doi:10.1080/ 09638237.2021 .1875412

33. Gurvich C, Thomas N, Thomas EHX, et al. Coping styles and mental health in response to societal changes during the COVID-19 pandemic. Int J Soc Psychiatry. 2020;67(5):540-549. doi:10.1177/0020764020961790

34. Juczynski Z, Ogińska-Bulik N. Narzędzia pomiaru stresu i radzenia sobie ze stresem [Measuring stress and coping with stress]. Warsaw: PTP 2009.

35. Dupuy HJ. The psychological general well-being (PGWB) index. In: Wenger NK, Mattson MEC, Furburg D, Elinson J, editors. Assessment of Quality of Life in Clinical Trials of Cardiovascular Therapies. New York: Le Jacq Publishing; 1990:170-183.

36. Grossi E, Groth N, Mosconi P, et al. Development and validation of the short version of the Psychological General Well-Being Index (PGWB-S). Health Qual Life Outcomes. 2006;4(1):88-96. doi:10.1186/1477-7525-4-88

37. Guszkowska M, Zagórska-Pachucka A, Kuk A, Skwarek K. Gender as a factor in differentiating strategies of coping with stress used by physical education students. Health Psychol Rep. 2016;4(3):237-245. doi:10.5114/hpr.2016.57681

38. Szczypińska M, Samełko A, Guszkowska M. What predicts the mood of athletes involved in preparations for Tokyo $2020 / 2021$ olympic games during the Covid-19 pandemic? The role of sense of coherence, hope for success and coping strategies. J Sports Sci Med. 2021;20:421-430. doi:10.52082/jssm.2021.421

39. Lyons Z, Wilcox H, Leung L, Dearsley O. COVID-19 and the mental well-being of Australian medical students: impact, concerns and coping strategies used. Australas Psychiatry. 2020;28(6):649-652. doi:10.1177/1039856220947945

40. Achlan I, Ochnik D, Çınar O. Exploring perceived stress among students in Turkey during the COVID-19 pandemic. Int J Environ Res Public Health. 2020;17(23):8961. doi:10.3390/ijerph17238961

41. Bourion-Bédès S, Tarquinio C, Batt M, et al. Stress and associated factors among French university students under the COVID-19 lockdown: the results of the PIMS-CoV 19 study. J Affect Disord. 2020;2020(283):108-114. doi:10.1016/j.jad.2021.01.041

42. Romero-Ramos N, Romero-Ramos O, Suarez AJG. Purpose in life during COVID-19 confinement: effect of physical activity and meditation. Polish J Sport Tourism. 2021;28(2):25-31. doi:10.2478/pjst-2021-0011

43. Guszkowska M. Aktywność Fizyczna i Psychika. Korzyści i Zagrożenia [Physical activity and psyche. Benefits and risks]. Toruń: Wydawnictwo Adam Marszałek; 2013.

44. Tejero-González CM. Participating in sports and practicing a religion are related to levels of happiness. Phys Cult Sport Studies Res. 2020;88 (1):11-17. doi:10.2478/pcssr-2020-0021

45. Brand R, Timme S, Nosrat S. When pandemic hits: exercise frequency and subjective well-being during COVID-19 pandemic. Front Psychol. 2020;11:570567. doi:10.3389/fpsyg.2020.570567

46. Sirois FM, Kitner R. Less adaptive or more maladaptive? A meta-analytic investigation of procrastination and coping. Eur $J$ Pers. 2015;29 (4):433-444. doi:10.1002/per.1985

47. Salman M, Noman A, Zia UM, et al. Psychological impairment and coping strategies during the COVID-19 pandemic among students in Pakistan: a cross-sectional analysis. Disaster Med Public Health Prep. 2021:1-6. doi:10.1017/dmp.2020.397.

48. Huang L, Lei W, Xu F, Liu H, Yu L. Emotional responses and coping strategies in nurses and nursing students during COVID-19 outbreak: a comparative study. PLoS One. 2020;15(8):e0237303. doi:10.1371/journal.pone.0237303

49. Hastings RP, Kovshoff H, Brown T, Ward NJ, Espinosa FD, Remington B. Coping strategies in mothers and fathers of preschool and school-aged children with autism. Autism. 2005;9(4):377-391. doi:10.1177/1362361305056078

50. Agha S. Mental well-being and association of the four coping structure model: a perspective of people living in lockdown during COVID-19. Ethics Med Public Health. 2020;16:100605. doi:10.1016/j.jemep.2020.100605 


\section{Publish your work in this journal}

Psychology Research and Behavior Management is an international, peer-reviewed, open access journal focusing on the science of psychology and its application in behavior management to develop improved outcomes in the clinical, educational, sports and business arenas. Specific topics covered in the journal include: Neuroscience, memory and decision making; Behavior modification and management; Clinical applications; Business and sports performance management; Social and developmental studies; Animal studies. The manuscript management system is completely online and includes a very quick and fair peer-review system, which is all easy to use. Visit http://www.dovepress.com/testimonials.php to read real quotes from published authors.

Submit your manuscript here: https://www.dovepress.com/psychology-research-and-behavior-management-journal 